\title{
Design and Control of Segmented Triple Three- Phase SPM Machines for Fault Tolerant Drives
}

\author{
G. Sala, D. Gerada, C. Gerada, IEEE Member, A. Tani
}

\begin{abstract}
A new multiphase Surface Permanent Magnet (SPM) machine design is investigated in this paper. The machine has a nine-phase winding arranged in three sectors and supplied by three different Voltage Source Inverters (VSI). Stator segmentation between these sectors is analyzed to improve the machine performance and fault tolerant behaviour. A new adaptable control technique is developed for the different segmentation geometries. Finite element simulations are used in order to validate the model and analyse possible layouts. Finally, an optimized design is proposed and the criticalities of the segmentation solution are explained.
\end{abstract}

Index Terms-Analytical models, brushless machines, fault tolerance, machine vector control, permanent magnet machines.

\section{INTRODUCTION}

$\mathrm{M}$ ULTIPHASE machines, compared to the standard three-phase ones, give more advantages in terms of reliability and efficiency, becoming always more suitable for high performance and fault tolerant applications. Multiphase motors allow exploiting more degrees of freedom in the generation of the armature field, which can be useful to obtain a higher torque density and efficiency, and reduced torque ripples [1]. Furthermore, suitable diagnostic and fault tolerant algorithms can be exploited also to detect fault conditions and/or to overcome them [2]-[3]. In general, a multiphase drive requires an "extended field oriented control" able to control the air-gap field harmonic components, and a multiphase modulation technique for the inverter can be used to increase the DC-bus exploitation [4]. Among the different multiphase machine topologies, the multi three-phase one has the advantage to use a standard three-phase inverter technology.

Multi three-phase machines can be wound with symmetrical three-phase windings. In this case each threephase winding is shifted from the others by a fixed and defined angle, allowing to better control the air-gap magnetic field [5]. Another possible solution is the sectored one, based on the redundant structure idea. This solution has been analyzed in [6], where two three-phase windings are separately arranged in different stator sectors without overlapping, to achieve higher electromagnetic independence.

In this paper a triple three-phase sectored winding configuration is analyzed. In this way the machine can be viewed as three machines which are exploded and joined

G. Sala and A. Tani are with the Department of Electric, Electronic and Information Engineering, Bologna University, Bologna, Italy (e-mail: giacomo.sala5@unibo.it; angelo.tani@unibo.it).

C. Gerada and D. Gerada are with the PEMC Group, Department of Electrical and Electronic Engineering, Faculty of Engineering, The University of Nottingham, Nottingham, NG7 2RD, U.K. (e-mail: chris.gerada@nottingham.ac.uk; david.gerada@nottingham.ac.uk). together to realize the triple three-phase sectored machine.

To emphasize the decoupling between the three-phase systems, the concept of segmentation is introduced. The idea is to increase the sector independence (mechanical, electromagnetic, thermal) without losing the machine performance. Previous works on stator segmentation have been carried out for manufacturing issues [7]-[8] or improving the motor performance [9]-[10], but in this paper this idea is applied for the first time to a distributed winding multi three-phase sectored machine to improve both the performance and the fault tolerant behaviour.

\section{SECTORED AND SEGMENTED MOtor DESIGN}

In this paper the idea of sectorization is used to define an electrical machine in which each three-phase winding is arranged in a different stator area and supplied by a threephase inverter. On the other hand, the concept of motor segmentation refers to the introduction of an additional material between the machine stator sectors.

Some analyzed designs, of sectored and segmented machines, are shown in Fig. 1, while the sectored winding scheme is illustrated in Fig. 2.

Hereafter the most important kind of analyzed segmented designs are referred to as "SDx", where $\mathrm{x}$ is the letter that distinguishes the different topologies, as shown in Fig. 1.

Once the segmentation is introduced, in the design optimization process there are a lot of new degrees of freedom which must be taken into account.

The main design variables, shown in Fig. 2, can be summarized as: segmentation thickness; segmentation material and shape; sector slots and teeth design. The rotor, the external stator diameter, the rated torque and the iron teeth and yoke area (in order to avoid iron saturation) are chosen as design constraints.

\section{A. Segmentation Thickness}

The segmentation thickness is the size of the gap introduced between the machine stator sectors. This gap is represented by the geometrical parameter $\Delta \Psi_{e s}$, shown in Fig. 2. The segmentation thickness affects the decoupling between the sectors, but also the available space, in each of

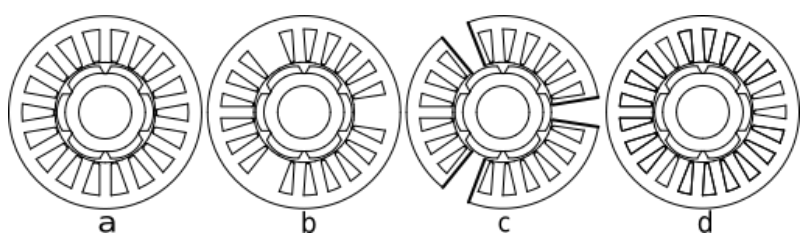

Fig. 1. Stator segmentation concept. a) Standard design "SDa". b) Full iron segmentation design "SDb". c) Full air segmentation design "SDc". d) 21 slots design "SDd" (Note that the "SDd" design has an odd number of slots). 
the three-phase sectors, to design the stator slots and teeth. If this available space decreases, the coil pitch inevitably changes, and this results in a new useful degree of freedom for the design. For example, the coil pitch can be exploited to reduce the most relevant armature fields (as the $5^{\text {th }}$ or/and the $\left.7^{\text {th }}\right)$. Furthermore, the segmented machine control technique (explained in Section IV) is strongly dependent on the segmentation thickness.

\section{B. Segmentation Material and Shape}

Once the segmentation thickness is defined, there is an available area that can be designed to improve the fault tolerant machine behaviour or to reduce the machine torque ripple. This area could also be exploited for an additional cooling system. It is possible to have a full iron segmentation (as SDb), an air based segmentation (as SDc), or a hybrid segmentation (as SDd). In this paper, the design process of the segmentation shape is conducted in order to avoid iron saturation, and to increase the frequency and decrease the amplitude of the cogging torque.

\section{Sector Slots and Teeth Design}

The sectors have been designed in order to have the same iron exploitation as in the standard SDa solution, i.e. the teeth thickness is the same for all the topologies shown in Fig. 1. The turns per phase number can be maintained the same as the SDa design or can be modified, as described in Section $\mathrm{V}$, to overcome the different magnetomotive force distribution caused by the new winding arrangement.

\section{FIELD ANALYSIS OF A TRIPLE THREE-PHASE SECTORED AND SEGMENTED SPM}

The segmentation between sectors (with an angle of $\left.\Delta \Psi_{e s}\right)$ is thoroughly investigated, together with the possibility to select a different number of turns between the central phase of each sector $\left(N_{c}\right)$ and the two external ones $\left(N_{e}\right)$. These design parameters are shown in Fig. 2.

In the proposed analysis the time dependence is implicit, the stator is supposed to be isotropic and the machine equations have been written in mechanical angles. It means that the main harmonic field is the $p$-th one $(\rho=p)$, with $p$ is the pole pair number. The parameters are defined as: $R$ the average air-gap radius; $\delta$ the magnetic air-gap thickness including the permanent magnets; $N_{S}$ the turns per slot number in the SDa machine design (and $N_{x}$ the actual number in the $x$-th phase); $\Delta \Psi_{s k}$ the coil pitch angle (that is equal to $\left.2 \pi / 2 p-\Delta \Psi_{e s} / 2\right) ; i_{\text {sxe }}$ the current in the $x$-phase under the $e$-sector, identified following the stator anticlockwise in Fig. $2(e(\mathrm{~A})=1, e(\mathrm{~B})=2, e(\mathrm{C})=3$, and so on till $e=p) ; \bar{i}_{s} \rho$ the $\rho$-th current space vector defined as

$$
\bar{i}_{s \rho}=\frac{2}{9} \sum_{x=1}^{3} \sum_{e=1}^{p} \frac{N_{x}}{N_{s}} i_{s x e} e^{j \rho \frac{2 \pi}{6 p}(x-2)} e^{j \rho \frac{2 \pi}{p}(e-1)} e^{-j \rho \frac{\Delta \Psi_{e s}}{2 p}(x-2)} .
$$

The resulting armature field, produced by the respective current distribution, is defined by the Fourier series

$$
H_{s}\left(\theta_{s}\right)=\sum_{\rho=1}^{\infty} \mathfrak{R}\left\{\bar{H}_{s \rho} e^{-j \rho \theta_{s}}\right\},
$$

where the coefficient that describes the $\rho$-th harmonic of the armature field is

$$
\bar{H}_{s \rho}=\frac{9 N_{s} \sin \left(\rho \Delta \Psi_{s k} / 2\right)}{\rho \pi \delta} \bar{i}_{s \rho},(\rho=1,2, \ldots, \infty) .
$$

Assuming that the machine is controlled with the same currents for each three-phase system, the SPM machine can be analyzed in the same way under each pole pair. With this choice, the control technique is defined for the main harmonic of the field, while the torque ripple and iron losses reduction are also related to the other harmonics of the field.

Hereafter the equations refer to a triple three-phase SPM machine (with $p=3$ ), and the three sectors are supposed to be controlled with the same currents.

In an SPM machine with 3 pole pairs, the only harmonic fields involved in the torque production are the ones with $\rho$ equal to $3 h$ and $h$ an odd non triple number. This allows rewriting (3) as

$$
\bar{H}_{s 3 h}=\frac{9 N_{s} \sin \left(\frac{3}{2} h\left(\frac{2 \pi}{6}-\frac{\Delta \Psi_{e s}}{2}\right)\right)}{3 h \pi \delta} \bar{i}_{s 3 h},(h=1,5,7, \ldots, \infty)
$$

The stator phase currents in one sector can also be well summarized by the standard three-phase current space vector representation (reported below for the sector A)

$$
\bar{i}_{S A}=\frac{2}{3} \sum_{x=1}^{3} i_{s x 1} \bar{\alpha}^{(x-1)}, \quad\left(\bar{\alpha}=e^{j \frac{2 \pi}{3}}\right) .
$$

As each three-phase system has its own star connection, the three-phase current space vectors $\left(\bar{i}_{S A}, \bar{i}_{S B}\right.$ and $\left.\bar{i}_{S C}\right)$ completely represent all the machine currents.

If $\bar{i}_{s A}, \bar{i}_{s B}$ and $\bar{i}_{S C}$ have the same value, it is easily possible to associate the generic current space vectors with the standard three-phase one. The connecting relation is

$$
\begin{aligned}
& \bar{i}_{s 3 h}=\frac{1}{3} \bar{i}_{s A}\left(\frac{N_{c}}{N_{s}}+\frac{N_{e}}{N_{S}} \bar{\beta}^{h} \bar{\alpha}^{(h-1)}+\frac{N_{c}}{N_{s}} \bar{\beta}^{-h} \bar{\alpha}^{2(h-1)}\right)+ \\
& +\frac{1}{3} \bar{i}_{s A}^{*}\left(\frac{N_{c}}{N_{s}}+\frac{N_{e}}{N_{s}} \bar{\beta}^{h} \bar{\alpha}^{(h+1)}+\frac{N_{c}}{N_{s}} \bar{\beta}^{-h} \bar{\alpha}^{2(h+1)}\right),
\end{aligned}
$$

where $\bar{\beta}$, that represents the main geometrical parameter which affects the armature field, is equal to $e^{j\left(\Delta \Psi_{e s} / 2\right)}$, and "*" is the complex conjugate. By (4)-(6) it is possible to evaluate the machine behaviour and improve it optimizing the design by the parameters $N_{x}$ and $\Delta \Psi_{e s}$.

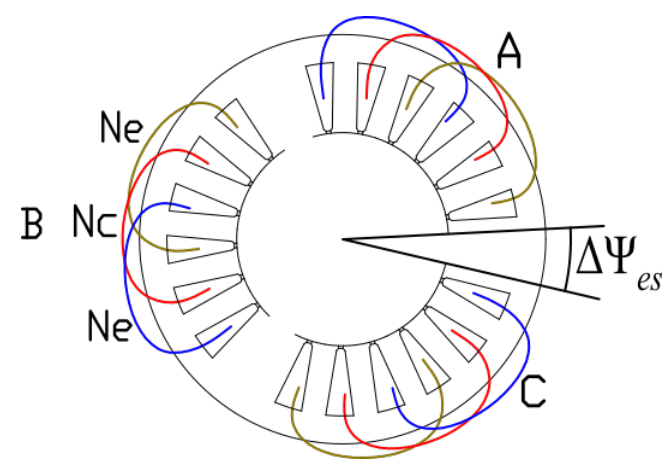

Fig. 2. Segmented triple three-phase machine stator, with sectored winding configuration, and main segmentation design parameters. 


\section{MACHINE CONTROL AND WINDING DESIGN}

The machine torque control coincides with the control of the armature field, that is mainly described by $\bar{H}_{s 3}$ (evaluable by (4) with $h=1$ ). To have a constant torque it is needed to maintain the q-axis component of the armature field in the rotor reference frame constant. In a standard control it means to have $\left|\bar{H}_{s 3}\right|$ constant, and so $\left|\bar{i}_{s 3}\right|$. If the machine is symmetrically controlled $\left(\bar{i}_{s A}=\bar{i}_{s B}=\bar{i}_{S C}\right), \bar{i}_{s 3}$ is obtained by (6) with $h$ equal to 1 .

Analyzing (6) it is possible to note two ways to have $\left|\bar{i}_{s}\right|$ constant: design the phase windings with a different number of turns per phase; maintain the standard winding design and change the control algorithm.

\section{A. New Windings Design for Standard Current Control}

In a standard machine control, in steady state conditions, the trajectory of the space vector $\bar{i}_{S A}$ is a circumference followed at constant speed. If this control is used in the new machine design with a standard winding configuration, the steady state torque is no more constant. There is a torque ripple at twice the electrical frequency $\left(f_{e}=f_{m} / p\right)$, related to the term containing $\bar{i}_{s A}^{*}$ in (6). Anyway, that term can be almost nullified if the following turn number constraint is satisfied:

$$
\frac{N_{c}}{N_{e}}=-2 \cos \left(\frac{\Delta \Psi_{e s}}{2}-\frac{2}{3} \pi\right)
$$

The control technique is not immediate when this winding solution is used, since the resistances and the back electromotive forces are not symmetrical in the phases of each sector. Therefore, an inverse voltage sequence in the machine control is needed, and it is necessary to have an additional regulator to maintain a zero inverse current sequence. This problem has been deeply analyzed in literature [2]-[3].

\section{B. Segmented Machine Control Technique for Standard Windings Designs}

If the machine is designed with a standard winding solution, to have a constant steady state torque a new control technique is needed. The proposed control technique is based on the relation between the main current space vector $\bar{i}_{s 3}$ and the three-phase one $\bar{i}_{S A}$, obtained by (6):

$$
\bar{i}_{S A}=\frac{3 \bar{i}_{s 3}\left(1+\bar{\beta}^{*}+\bar{\beta}\right)-3 \bar{i}_{S 3}^{*}\left(1+\bar{\beta} \bar{\alpha}^{2}+\bar{\beta}^{*} \bar{\alpha}\right)}{\left(1+\bar{\beta}^{*}+\bar{\beta}\right)^{2}-\left(1+\bar{\beta}^{*} \bar{\alpha}+\bar{\beta} \bar{\alpha}^{2}\right)\left(1+\bar{\beta} \bar{\alpha}^{2}+\bar{\beta}^{*} \bar{\alpha}\right)} .
$$

It is worth noticing that this is not a standard control technique, since it needs an inverse sequence current control. Indeed, the resulting $\bar{i}_{s 3}$ vector moves on a circumference at constant speed. If this happens, it follows that (6) describes $\bar{i}_{S A}$ as a vector moving on an ellipse, that can be analyzed as the sum of two components

$$
\bar{i}_{\text {sA }}=\bar{i}_{\text {sAdir }}+\bar{i}_{\text {sAinv }} \text {, }
$$

with

$$
\bar{i}_{\text {sAdir }}=\frac{3 \bar{i}_{s 3}\left(1+\bar{\beta}^{*}+\bar{\beta}\right)}{\left(1+\bar{\beta}^{*}+\bar{\beta}\right)^{2}-\left(1+\bar{\beta}^{*} \bar{\alpha}+\bar{\beta} \bar{\alpha}^{2}\right)\left(1+\bar{\beta} \bar{\alpha}^{2}+\bar{\beta}^{*} \bar{\alpha}\right)},
$$

$$
\bar{i}_{\text {sAinv }}=\frac{-3 \bar{i}_{s 3}^{*}\left(1+\bar{\beta} \bar{\alpha}^{2}+\bar{\beta}^{*} \bar{\alpha}\right)}{\left(1+\bar{\beta}^{*}+\bar{\beta}\right)^{2}-\left(1+\bar{\beta}^{*} \bar{\alpha}+\bar{\beta} \bar{\alpha}^{2}\right)\left(1+\bar{\beta} \bar{\alpha}^{2}+\bar{\beta}^{*} \bar{\alpha}\right)} .
$$

The space vectors $\bar{i}_{\text {sAdir }}$ and $\bar{i}_{\text {sAinv }}$ move on circumferences at the same angular speed but in opposite directions. Specifically, the inverse sequence space vector $\bar{i}_{\text {SAinv }}$ moves with an opposite direction from $\bar{i}_{s 3}$.

\section{CoIl Pitch, END EFFECT AND COGGING TORQUE IN SEGMENTED SECTORED MACHINES}

Since the stator segmentation changes the coil pitch, it can be exploited to reduce the most relevant armature fields. On the other hand, this causes an asymmetry in the stator geometry that introduces a torque ripple that can be seen as a machine end effect.

\section{A. Coil Pitch}

In order to evaluate the effect of the coil pitch on the armature field, the evaluated maximum magnitudes of the most important harmonic fields varying the segmentation thickness are shown in Fig. 3.

The parameters of the analyzed unsegmented machine are described in Table I, and the plots in Fig. 3 are evaluated by (4) and (6) keeping the same value of the current space vector $\bar{i}_{s 3}$, as in the control proposed in Section IV-B, while the segmentation thickness $\Delta \Psi_{e s}$ is changed and each phase has $N_{s}$ turns. As shown in Fig. 3, it is possible to completely eliminate the $5^{\text {th }}$ or the $7^{\text {th }}$ harmonics and the related torque ripples. It must be noticed that a higher segmentation causes a lower main harmonic field and a reduction of the slot areas, so it is preferable to find a solution with a small thickness.

\section{B. End Effect and Cogging Torque}

It is well known that to deal with the end effect, in the design of linear machines, it is possible to shape the end geometries by Finite Element Analysis (FEA) and optimization algorithms. Similar solutions can be adopted for the segmented motor design, but with the difference that the machine is still a rotary one. The segmentation end effect depends on the segmentation thickness, and even more on the segmentation material. FEA analysis has been performed to analyze the different design solutions.

On the other hand, an alternative solution has been deduced on the idea of having the smallest polar symmetry of the stator. It means that it is possible to design a segmented

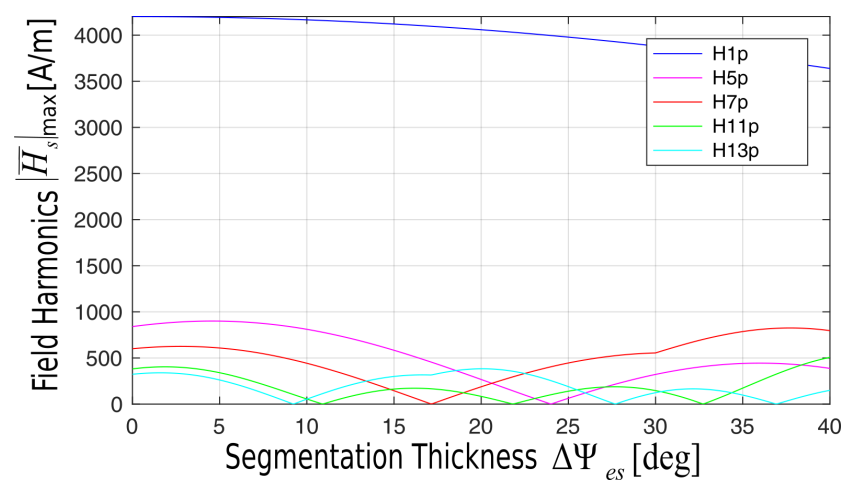

Fig. 3. Maximum amplitude of the magnetic field harmonics varying the angle $\Delta \Psi_{e s}$. 
machine adding some empty slots (without flowing currents) in the gap between two sectors (as in SDd with one added slot between the sectors). This solution allows having a symmetrical stator geometry and, in this way, the torque ripple can be analyzed as a cogging torque.

The mechanical cogging torque frequency in a $2 p$-poles $N_{\text {slots }}$-slots machine, rotating at mechanical frequency $f_{m}$, is

$$
f_{\text {cogging }}=\operatorname{lcm}\left(2 p, N_{\text {slots }}\right) f_{m},
$$

where $l \mathrm{~cm}$ is the least common multiple. The relative electrical frequency is equal to $f_{\text {cogging }} / p$. In the analyzed machine design, the first solution (adding 1 empty slot between each sector pair) is the one with 21 slots (SDd). The relative cogging torque frequency is $42 f_{m}$, and it is a practical design solution, since it corresponds to a segmentation thickness of about 17 degrees. This means, from the analysis shown in Fig. 3, that the $7^{\text {th }}$ harmonic armature field is deleted. Because of the analytical evaluation and the obtained FE results, this paper analyzes the three design solutions shown in Fig. 1. All of them have a segmentation with $\Delta \Psi_{\text {es }}$ of about 17 degrees.

\section{SimUlation RESUlTS}

The analytical and theoretical results have been verified by FEA in Magnet ${ }^{\mathrm{TM}}$. The SDa machine main data are reported in Table I.

\section{A. Performance - Healthy Machine Behaviour}

The analysis is carried out at about rated current, and in all the following figures the FFT spectra are translated from the SDa spectra for a good comparison between the designs.

\section{a) Armature Field}

The decision of the segmentation thickness has been carried out to delete some field harmonics in the air-gap, as discussed in Section V. With a 10 A peak current and a standard machine control, the spatial distribution of the armature flux in the SDa-SDd designs is shown in Figs. 4-5.

As predicted in Section V (Fig. 3), the $21^{\text {st }}\left(7^{\text {th }}\right)$ armature field is almost deleted in all the new designs and the $15^{\text {th }}\left(5^{\text {th }}\right)$ is significantly reduced.

The spatial distribution of the armature flux in Fig. 4 is not
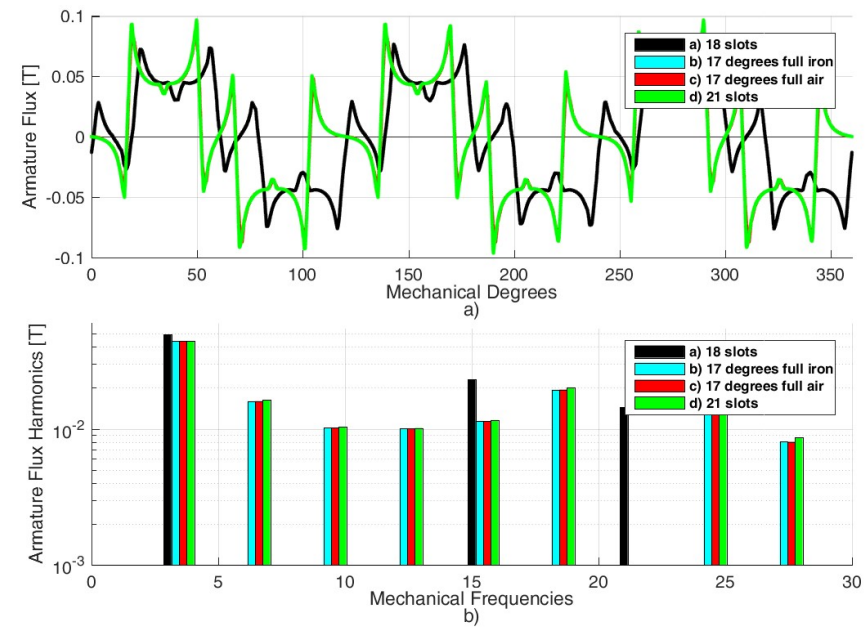

Fig. 4. SDa-SDd design armature fluxes a), and their FFT spectra b), in the minimum reluctance configuration. enough to analyze the machine behaviour, due to the asymmetrical design. Indeed, it is also needed to study its shape in the maximum reluctance configuration, as in Fig. 5.

Comparing Figs. 4-5, it is possible to evaluate the amplitude of the inverse sequence harmonics of the armature field. The amplitude of each inverse sequence harmonic is equal to half the difference between the minimum and maximum values of the respective harmonic of the spatial distribution, shown in the FFT spectra in Fig. 4-b and Fig.5b. These inverse fields are deeply investigated in the machine analysis.

\section{b) Cogging Torque}

A comparison between the cogging torque of the investigated designs is shown in Fig. 6.

As predicted by (12), the cogging torque main harmonic is at $18 f_{m}$ and $42 f_{m}$ for the SDa and SDd designs respectively, with a really reduced amplitude for the SDd one. Instead, the cogging torque of the $\mathrm{SDb}$ and $\mathrm{SDc}$ designs is significantly worse.

\section{c) Torque - New Control Technique}

The torque of the four machine designs controlled in a standard way is shown in Fig. 7. From the spectra in Fig. 7 it is possible to notice a high torque ripple at $6 f_{m}\left(2 f_{e}\right)$.

To overcome this ripple, the new control described in Section IV is applied. The resulting torque is shown in Fig. 8. The inverse field of the main harmonic is almost deleted with the new control (with worst results for the SDc design). This control allows having comparable torque performance among the SDa, SDb and SDd designs.

The different design performance, with the new control technique, are summarized in Table II.

The same slot fill factor used to simulate the different designs explains the higher phase resistance and Joule losses values.

d) SDd Torque - New Winding Design

The SDd machine is the one with better performance (especially at no load), and that is why in Fig. 9 the new winding solution is reported and compared with the new control technique one only for this design.

In this case the central windings have 16 turns rather than 22. As can be seen from Fig. 9, the new winding solution
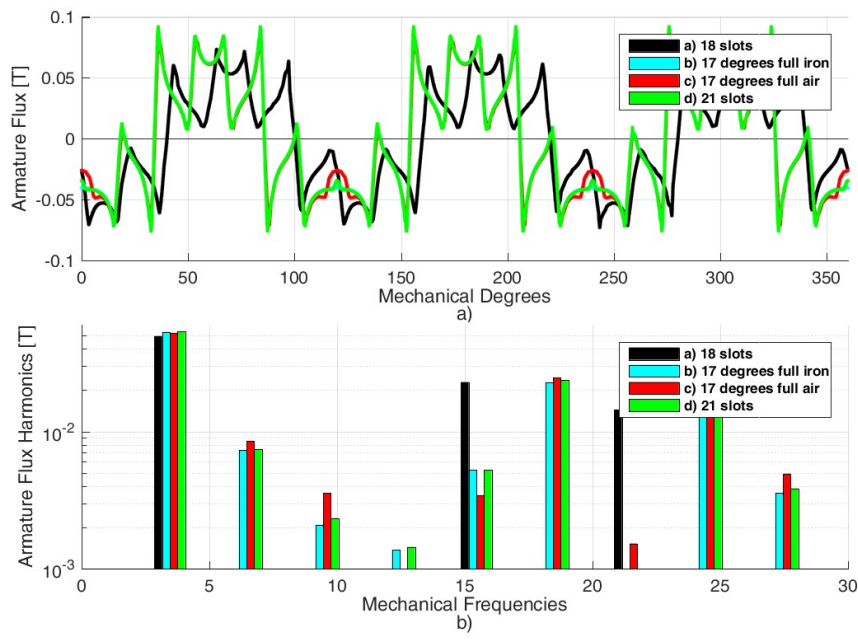

Fig. 5. SDa-SDd designs armature fluxes a), and their FFT spectra b), in the maximum reluctance configuration. 
defined in Section IV has almost the same advantages of the new control technique in terms of resulting torque.

\section{B. Fault Tolerant Behaviour}

The fault tolerant behaviour has been evaluated in terms of sectors decoupling, and for open winding and short circuit faults.

\section{a) Inductances Analysis}

In terms of fault tolerant behaviour, one of the most significant parameter is the ratio between self and mutual inductances. In a sectored multi three-phase machine, and even more in a segmented one, the mutual inductance value between phases of different sectors becomes the most important for this analysis [6]. The self and mutual inductances are shown in Table III for all the designs.

It has been found that the SDb and SDd have almost the same self and mutual inductances. A better solution is instead obtained with the full air segmented design (SDc).

\section{b) Open Winding and Short Circuits}

In terms of one sector open winding behaviour, it is possible to compensate for the fault just by increasing the reference current amplitudes in the healthy phases. The open
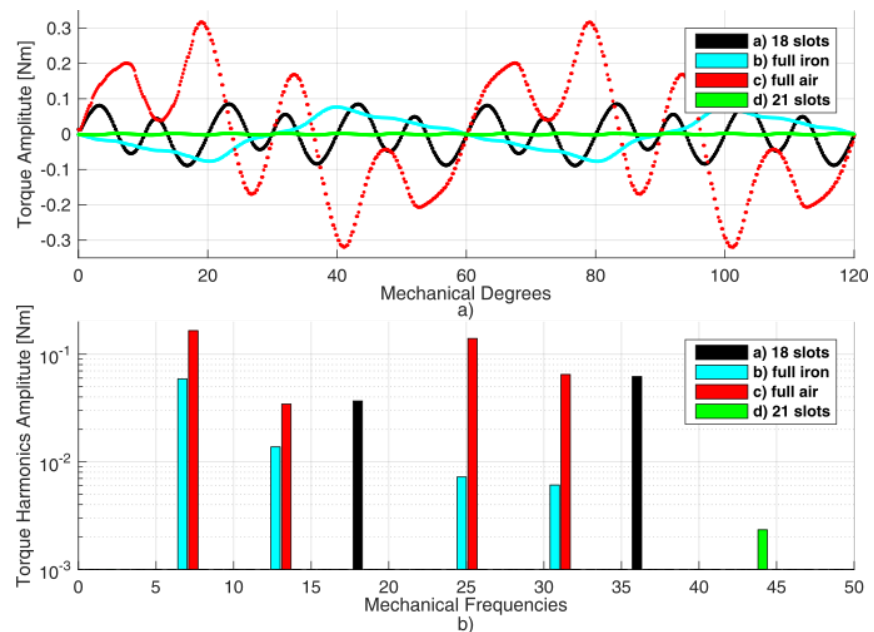

Fig. 6. Cogging torque of all the SDa-SDd designs a), and its FFT spectrum b).
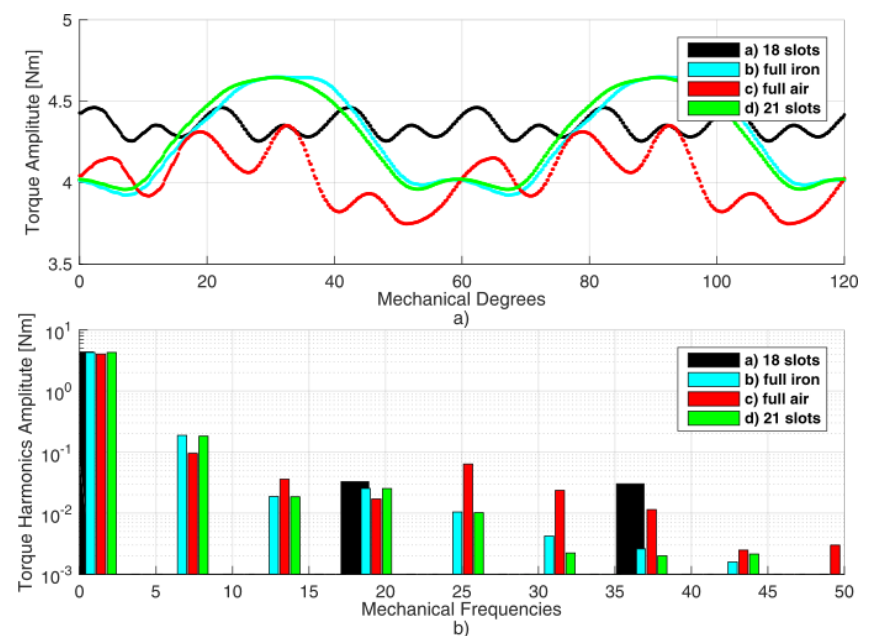

Fig. 7. Torque of the SDa-SDd designs a), and its FFT spectrum b). With standard control technique. winding performance is almost the same in all the designs. The short circuit machine performance for a one sector threephase short circuit fault, instead, are increased in the segmented designs, with reduced torque, radial force ripples and short circuit current. FEA results are shown in Table IV.

\section{CONCLUSION}

An overview of the segmentation design for a triple threephase sectored SPM machine has been presented. A new control technique is proposed to overcome the drawbacks introduced by the stator segmentation. A possible alternative to the new machine control, based on a different winding design, has also been presented. Between the proposed stator geometries, the one with a complete air segmentation, such as SDc, has the higher decoupling between the sectors, but it shows worse performance. Instead, the chosen design (SDd) has significantly better performance. The feasibility to increase the sector decoupling (mechanical, magnetic and thermal) by the stator segmentation has been proven for all the designs, with additional advantages under short circuit conditions.
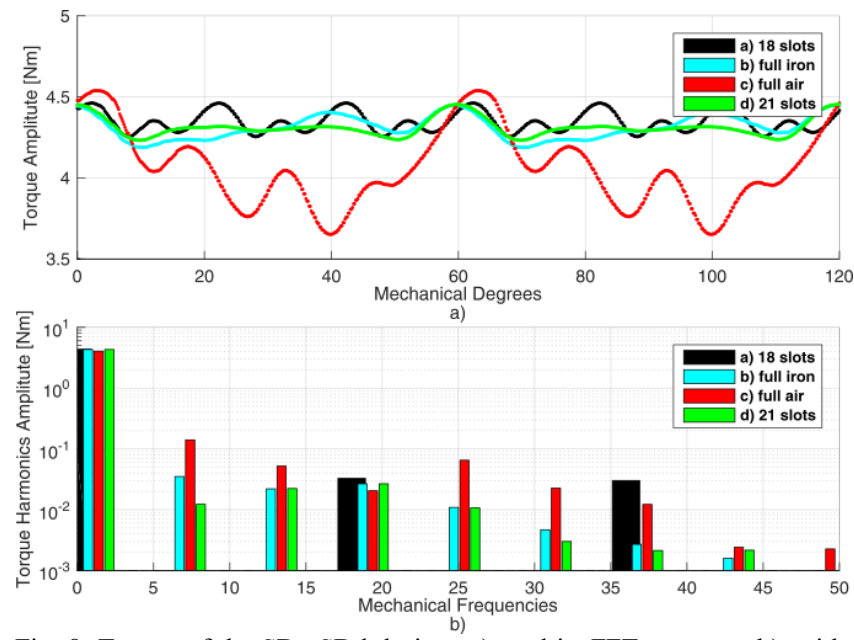

Fig. 8. Torque of the SDa-SDd designs a), and its FFT spectrum b), with new control technique.
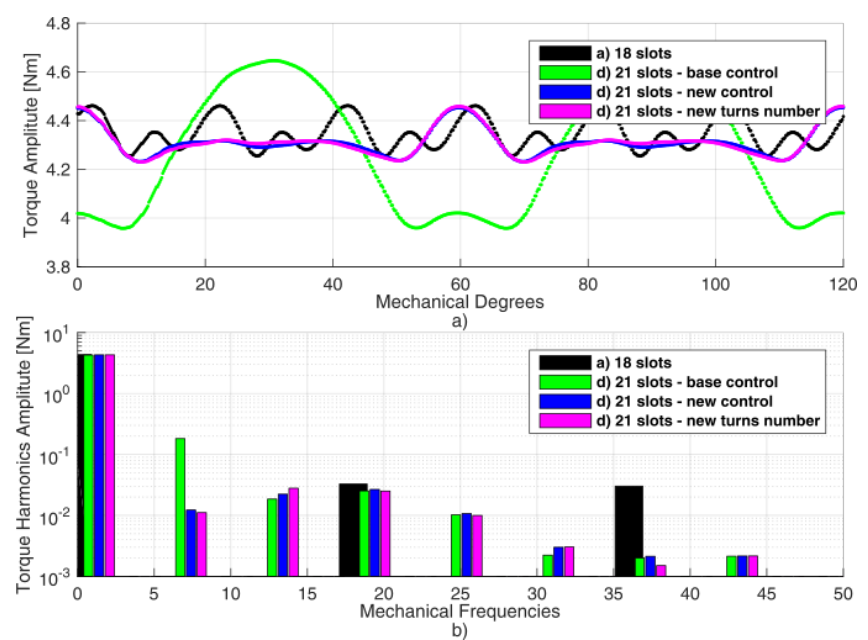

Fig. 9. Torque comparison between the standard SDa motor and the new 21 slots SDd machine design with the standard control technique, the new control technique and the 16 central turns solution. Torque plots a), and logarithmic FFT spectrum b). 
TABLE I

MAIN PARAMETERs OF THE ANALYZED Nine-Phase SPM MACHINE [11]. MACHINE PARAMETERS

\begin{tabular}{ll}
\hline Pole number $(2 p)$ & 6 \\
PM material & $\mathrm{NdFeB}$ \\
$\mathrm{kW}$ Rating & $1.5 \mathrm{~kW}$ \\
Turn/coil & 22 \\
No Load Flux/sector & $0.026 \mathrm{~Wb}$ \\
Rated Speed & $3000 \mathrm{rpm}$ \\
Torque constant & $0.128 \mathrm{Nm} / \mathrm{A}$ \\
Voltage constant & $6.022 \mathrm{~V} / \mathrm{krpm}$ \\
Phase resistance $\left(\mathrm{R}_{\mathrm{ph}}\right)$ & $0.0808 \mathrm{Ohm}$
\end{tabular}

TABLE II

HEALTHY MACHINE BEHAVIOUR.

\begin{tabular}{|c|c|c|c|c|}
\hline & Sda & SDb & SDc & SDd \\
\hline Torque [Nm] & 4.35 & 4.31 & 4.06 & 4.31 \\
\hline Torque ripple (pp) [Nm] & 0.21 & 0.26 & 0.89 & 0.22 \\
\hline R phase [Ohm] & 0.08 & 0.11 & 0.11 & 0.11 \\
\hline PJ Copper mean [W] & 36.00 & 51.48 & 51.48 & 51.48 \\
\hline I max [A] & 10.00 & 10.65 & 10.65 & 10.65 \\
\hline V max [V] & 30.31 & 32.09 & 30.55 & 31.82 \\
\hline
\end{tabular}

\section{REFERENCES}

[1] L. Parsa and H. A. Toliyat, "Five-phase permanent-magnet motor drives," in IEEE Trans. on Industry Applications, vol. 41, no. 1, pp. 30-37, Jan.-Feb. 2005.

[2] A. Tani, M. Mengoni, L. Zarri, G. Serra and D. Casadei, "Control of multiphase induction motors with an odd number of phases under open-circuit phase faults," in IEEE Trans. on Power Electronics, vol. 27, no. 2, pp. 565-577, Feb. 2012.

[3] A. Tani, Y. Gritli, M. Mengoni, L. Zarri, G. Sala, A. Bellini, G. Serra and "Detection of magnet demagnetization and high-resistance connections in five-phase surface-mounted permanent magnet generators," Diagnostics for Electrical Machines, Power Electronics and Drives (SDEMPED), 2015 IEEE 10th International Symposium on, Guarda, Portugal, 2015, pp. 487-493.

[4] D. Casadei, D. Dujic, E. Levi, G. Serra, A. Tani and L. Zarri, "General modulation strategy for seven-phase inverters with independent control of multiple voltage space vectors," in IEEE Trans. on Industrial Electronics, vol. 55, no. 5, pp. 1921-1932, May 2008.

[5] A. Tani, G. Serra, M. Mengoni, L. Zarri, G. Rini and D. Casadei, "Dynamic stator current sharing in quadruple three-phase induction motor drives," Industrial Electronics Society, IECON 2013 - 39th Annual Conf. of the IEEE, Vienna, Austria, 2013, pp. 5173-5178.

[6] M. Barcaro, N. Bianchi and F. Magnussen, "Analysis and tests of a dual three-phase 12-slot 10-pole permanent-magnet motor," in IEEE Trans. on Industry Applications, vol. 46, no. 6, pp. 2355-2362, Nov.Dec. 2010.

[7] B. Bickel, J. Franke and T. Albrecht, "Manufacturing cell for winding and assembling a segmented stator of PM-synchronous machines for hybrid vehicles," Electric Drives Production Conf. (EDPC), 2012 2nd International, Nuremberg, 2012, pp. 1-5.

[8] J. Brettschneider, R. Spitzner and R. Boehm, "Flexible mass production concept for segmented BLDC stators," Electric Drives Production Conf. (EDPC), 2013 3rd International, Nuremberg, Germany, 2013, pp. 1-8.

[9] G. J. Li, Z. Q. Zhu, W. Q. Chu, M. P. Foster and D. A. Stone, "Influence of flux gaps on electromagnetic performance of novel modular PM machines," in IEEE Trans. on Energy Conversion, vol. 29, no. 3, pp. 716-726, Sept. 2014.

[10] N. S. Lobo, E. Swint and R. Krishnan, "M-Phase N-Segment fluxreversal-free stator switched reluctance machines," Industry Applications Society Annual Meeting, 2008. IAS '08. IEEE, Edmonton, Canada, 2008, pp. 1-8.

[11] G. Valente, L. Papini, A. Formentini, C. Gerada and P. Zanchetta, "Radial force control of multi-sector permanent magnet machines," 2016 XXII International Conf. on Electrical Machines (ICEM), Lausanne, Switzerland, 2016, pp. 2595-2601.
TABLE III

SELF AND MUTUAL INDUCTANCES BETWEEN PHASES ON THE SAME SECTOR (UNDERLINED) AND NOT. RESULTS WHEN PHASE UA AND VA ARE FED, IN THE TOP (YELLOW) AND BOTTOM (BLUE) RESPECTIVELY.

\begin{tabular}{|c|c|c|c|c|c|c|c|c|c|}
\hline [mH] & MUCUA & MVCUA & MWCUA & MVAUA & LUA & MWAUA & MVBUA & MUBUA & MWBUA \\
\hline SDa (18 slots) & 0.028 & 0.028 & 0.029 & 0.087 & 0.310 & 0.087 & 0.029 & 0.028 & 0.028 \\
\hline SDb (full iron) & 0.021 & 0.021 & 0.021 & 0.080 & 0.404 & 0.080 & 0.021 & 0.021 & 0.021 \\
\hline SDc (full air) & 0.014 & 0.014 & 0.014 & 0.063 & 0.386 & 0.063 & 0.014 & 0.014 & 0.014 \\
\hline SDd (21 slots) & 0.021 & 0.021 & 0.021 & 0.083 & 0.408 & 0.083 & 0.021 & 0.021 & 0.021 \\
\hline \hline [mH] & MUCVA & MVCVA & MWCVA & LVA & MUAVA & MWAVA & MVBUA & MUBUA & MWBVA \\
\hline SDa (18 slots) & 0.029 & 0.028 & 0.029 & 0.310 & 0.087 & 0.030 & 0.028 & 0.028 & 0.028 \\
\hline SDb (full iron) & 0.021 & 0.021 & 0.021 & 0.406 & 0.083 & 0.033 & 0.021 & 0.021 & 0.021 \\
\hline SDc (full air) & 0.013 & 0.013 & 0.013 & 0.338 & 0.065 & 0.015 & 0.013 & 0.013 & 0.013 \\
\hline SDd (21 slots) & 0.021 & 0.021 & 0.021 & 0.402 & 0.080 & 0.030 & 0.021 & 0.021 & 0.021 \\
\hline
\end{tabular}

TABLE IV

COMPENSATED OPEN WINDING AND SHORT CIRCUIT BEHAVIOUR.

\begin{tabular}{|c|c|c|c|c|c|c|c|c|}
\cline { 2 - 10 } \multicolumn{1}{c|}{} & \multicolumn{4}{c|}{ open winding } & \multicolumn{4}{c|}{ short circuit } \\
\hline & Sda & SDb & SDc & SDd & Sda & SDb & SDc & SDd \\
\hline Torque [Nm] & 4.3 & 4.3 & 4.0 & 4.3 & 1.6 & 1.9 & 1.6 & 1.7 \\
\hline Torque ripple $(\mathrm{pp})[\mathrm{Nm}]$ & 0.21 & 0.26 & 0.85 & 0.23 & 4.40 & 0.74 & 2.04 & 0.85 \\
\hline R phase [Ohm] & 0.08 & 0.11 & 0.11 & 0.11 & 0.08 & 0.11 & 0.11 & 0.11 \\
\hline PJ Copper mean [W] & 54 & 78 & 78 & 78 & 476 & 445 & 470 & 442 \\
\hline I max [A] & 15.0 & 16.0 & 16.0 & 16.0 & 74.6 & 52.6 & 53.0 & 52.7 \\
\hline V max [V] & 32.0 & 33.1 & 31.7 & 33.1 & 34.1 & 33.7 & 32.0 & 33.8 \\
\hline V max faulty phases [V] & 31.0 & 30.5 & 29.0 & 30.4 & 2.9 & 1.2 & 1.5 & 1.0 \\
\hline Radial Force [N] & 39 & 63 & 66 & 62 & 491 & 429 & 429 & 426 \\
\hline Force ripple (pp) [N] & 52 & 59 & 43 & 58 & 307 & 91 & 106 & 94 \\
\hline
\end{tabular}

\section{BIOGRAPHIES}

Giacomo Sala was born in Vercelli, Italy, in 1990. He received the B. Sc. in Power Engineering in 2012 and the M. Sc. degree in Electrical Engineering, with honors, in 2014 from the University of Bologna, Bologna, Italy. Since 2014 he has been working toward the Ph.D. degree at the Department of Electrical, Electronic and Information Engineering, University of Bologna. $\mathrm{He}$ is currently involved in a project on multiphase fault tolerant drives control and design with the Power Electronics, Machines and Control Group, Department of Electrical and Electronic Engineering, Faculty of Engineering, The University of Nottingham, Nottingham. His research interests include fault tolerant and sensorless control of multiphase drives, and fault diagnosis of electrical machines.

David Gerada received the B.Eng.(Hons.) degree in electrical engineering from the University of Malta, Malta in 2007 and the Ph.D. degree in highspeed electrical machines from the University of Nottingham, Nottingham, UK in 2012. From 2007-2015 he was with the R\&D Department at Cummins Generator Technologies, Stamford, UK, first as an Electrical Machine Design Engineer (2007-2011) and then as a Senior Electrical Machine Design Engineer and Innovation Leader (2011-2016). In 2016 he joined the University of Nottingham as a Senior Research Fellow in Electrical Machines. His research interests include high speed machines, traction machines, use of novel materials, and multiphysics-based optimization of electrical machines. Dr. Gerada is a Chartered Engineer in the U.K. and a member of the Institution of Engineering and Technology.

Chris Gerada (SM'14) received the Ph.D. degree in numerical modeling of electrical machines from The University of Nottingham, U.K., in 2005 . $\mathrm{He}$ was a Researcher with The University of Nottingham, working on highperformance electrical drives and design and modeling of electromagnetic actuators for aerospace applications. He became a Lecturer in Electrical Machines in 2008, an Associate Professor in 2011, and a Professor in Electrical Machines in 2013 at The University of Nottingham. He currently holds the Royal Academy of Engineering/Cummins Chair in Electrical Machines at The University of Nottingham. His research interests include the design and modeling of high-performance electric drives and machines. Prof. Gerada is an Associate Editor for the IEEE TRANS. ON INDUSTRY APPLICATIONS and is the Chair of the IEEE Industrial Electronics Society Electrical Machines Technical committee.

Angelo Tani was born in Faenza, Italy, in 1963. He received the M. Sc. in Electrical Engineering, with honors, from the University of Bologna, Bologna, Italy, in 1988. Currently he is an Associate Professor with the Department of Electric, Electronic and Information Engineering, University of Bologna. He has authored more than 150 papers published in technical journals and Conf. proceedings. His current activities include multiphase motor drives, ac/ac matrix converters, and field weakening strategies for induction motor drives. 